\title{
Efficacy and safety of artesunate plus amodiaquine in routine use for the treatment of uncomplicated malaria in Casamance, southern
} Sénégal

\author{
Philippe Brasseur ${ }^{1}$, Patrice Agnamey ${ }^{2}$, Oumar Gaye ${ }^{3}$, Michel Vaillant ${ }^{4,5}$, \\ Walter RJ Taylor ${ }^{6,7}$ and Piero L Olliaro*5,7
}

Address: ${ }^{1}$ UR 077, IRD, Dakar, Sénégal, ${ }^{2}$ Laboratoire de Parasitologie-Mycologie CHU Amiens, France, ${ }^{3}$ Faculté de Médecine, Université Cheikh Anta Diop, Dakar, Sénégal, ${ }^{4}$ Clinical Epidemiology and Public Health Unit, Center for Health Studies, CRP-Santé, Luxembourg, ${ }^{5}$ Unité 3677 , Bases thérapeutiques des inflammations et infections, Université Victor Segalen Bordeaux 2, Bordeaux, France, ${ }^{6}$ Travel and Migration Medicine Unit, Geneva University Hospital, Geneva, Switzerland and ${ }^{7}$ UNICEF/UNDP/WB/WHO Special Programme for Research \& Training in Tropical Diseases (TDR), 20 avenue Appia, CH1211 Geneva 27, Switzerland

Email: Philippe Brasseur - brasseur@ird.sn; Patrice Agnamey - agnamey.patrice@chu-amiens.fr; Oumar Gaye - ogaye@refer.sn; Michel Vaillant - michel.vaillant@crp-sante.lu; Walter RJ Taylor - bobtaylor@oucru.netnam.vn; Piero L Olliaro* - olliarop@who.int

* Corresponding author

Published: 15 November 2007

Malaria Journal 2007, 6:150 doi:10.1186/1475-2875-6-150
Received: 12 June 2007

Accepted: 15 November 2007

This article is available from: http://www.malariajournal.com/content/6/1/150

(c) 2007 Brasseur et al; licensee BioMed Central Ltd.

This is an Open Access article distributed under the terms of the Creative Commons Attribution License (http://creativecommons.org/licenses/by/2.0), which permits unrestricted use, distribution, and reproduction in any medium, provided the original work is properly cited.

\begin{abstract}
Background: There are no data on the long term use of an artemisinin combination treatment in moderate or high transmission areas of Africa.

Methods and findings: Artesunate plus amodiaquine (AS+AQ) was used to treat slide-proven Plasmodium falciparum-infected patients of all ages in the Oussouye district, Casamance, Senegal, over a period of six years (2000 to 2005). Efficacy, by Kaplan Meier survival analysis $(n=966)$, and safety (adverse event rates, $n=752$ ) were determined over 28 days. A weight-based dosing regimen was used for the loose tablets during 2000-2003 $(n=73 \mathrm{I})$ and a commercially available co-blister was used during 2004-2005 ( $\mathrm{n}=235)$.

Annual crude (non PCR corrected) rates remained stable over the study period [range 88.5-96.7\%; overall $94.6(95 \% \mathrm{Cl} 92.9-95.9)]$. Nine co-blister treated patients $(0.9 \%)$ withdrew because of drugrelated adverse events; seven had gastrointestinal complaints of whom two were hospitalized for vomiting. By Day 28 , the mean total bilirubin $(n=72)$, AST $(n=94)$ and ALT $(n=95)$ values decreased. Three patients had Day 28 AST/ALT values $>40<200 \mathrm{IU} / \mathrm{L}$. Changes in white cell counts were unremarkable $(n=87)$.

Conclusion: AS+AQ in combination was highly efficacious and well-tolerated in this area and justifies the decision to use it as first line treatment. Long-term monitoring of safety and efficacy should continue.
\end{abstract}

\section{Background}

Artemisinin-containing combination therapies (ACTs) are now being deployed in some 42 malaria endemic coun- tries and a further 26 have agreed to adopt ACTs following the World Health Organization (WHO) recommendation that ACTs should be the first line drugs for treating 
uncomplicated falciparum malaria (data provided by WHO/GMP, February 2007).

Artesunate plus amodiaquine (AS+AQ) is one of the currently available ACTs and is in use in Indonesia and 18 African countries (Burundi, Cameroon, Congo, Côte d'Ivoire, Democratic Republic of Congo, Equatorial Guinea, Gabon, Ghana, Guinea, Liberia, Madagascar, Malawi, Mauritania, Senegal, Sao Tome \& Principe, Sierra Leone, Sudan (South), Zanzibar).

Because the WHO policy change is recent, there is, to date, little experience with the systematic use of these drugs in malaria endemic countries. The most reliable data regarding systematic use comes from the low transmission areas of the Thai Burmese border where artesunate plus mefloquine has been in continuous use since the early 1990s, well before the WHO recommendation. This combination has consistently produced high cure rates, achieved a reduction in the transmission of Plasmodium falciparum while the trend of increasing in vitro mefloquine resistance has been reversed $[1,2]$. Similar results have been reported with the deployment of artemether/lumefantrine (Coartem $^{\circledast}$ ) in another low-transmission area on the South Africa-Mozambique border, where the malaria burden has fallen and where there has been a reduction in morbidity and mortality [3].

By contrast, there are no reported data on the long term use of ACTs from areas of higher malaria transmission. Having this information is important because areas of moderate and high transmission account for most of the global malaria burden and experience from areas of low transmission may not necessarily be applied to higher transmission settings [4]. In addition, the useful therapeutic life spans of the ACTs may vary with transmission intensity and with such factors like cost, compliance and treatment seeking behaviour.

This paper reports on the safety and efficacy of AS+AQ in the chloroquine-resistant, Oussouye district of southern Casamance, Senegal, during 2000-2005 for treating patients with parasitologically confirmed falciparum malaria.

\section{Methods}

\section{Study site characteristics}

This study was conducted at the outpatient clinics of four dispensaries (Mlomp, Oussouye, Kabrousse and Djembereng) all situated in the District of Oussouye, southern Casamance. The total population of the district is circa 70,000 , mostly farmers. Malaria transmission is perennial and meso-endemic with an increase in cases during the rainy season (July to December). The entomological inoculation rate is 25 infected bites per person-year [5].
In this area, the rate of chloroquine-resistant strains has remained stable at around 66\% between 1997 and 2004 [6]. Despite this high rate, trials over the past decade have shown that AQ alone or combined with AS are efficacious [7-9].

\section{Study methodology}

This was a non-comparative assessment of the efficacy and safety of AS plus AQ conducted over 28 days. Potentially eligible patients of all ages who attended the clinic with either a history of fever or a confirmed fever (measured axillary temperature $\geq 37.5^{\circ} \mathrm{C}$ ) and a positive Giemsastained thick film for $P$. falciparum were briefed about the study and those who gave their written informed consent were registered and their houses were mapped. Entry criteria included: weight $>5 \mathrm{~kg}$; male and non-pregnant or breast-feeding female; living in the study area (for ease of follow-up); having given informed consent to participate; fever or history of fever; falciparum parasitaemia 1,000200,000 parasites $/ \mu \mathrm{L}$; no antimalarial drug intake in the previous week; able to take oral drugs; no signs/symptoms of severe malaria; no major intercurrent illness or history of cardiac, hepatic or renal disorder; no known allergy to study drugs. The study was approved by the Senegalese National Ethical Committee.

All eligible patients were treated with AS + AQ. Initially (2000-2001), the use of AS+AQ was restricted to the rainy season, and later extended (2002-2005) to all year round. During 2000-2003, loose tablets were used in combination and patients were dosed by body weight. Subsequently a blister pack containing both drugs became available during 2004-2005 and patients were dosed by age (except 30 subjects in 2004 who were dosed by weight). The drugs used were:

- loose combination: Arsumax ${ }^{\circledast}$ tablets (Sanofi-Aventis) containing $50 \mathrm{mg}$ of AS and Camoquin ${ }^{\circledast}$ tablets (ParkeDavis) containing $200 \mathrm{mg}$ of AQ base tablets. The doses used were $4 \mathrm{mg} / \mathrm{kg} /$ day (AS) and $10 \mathrm{mg} / \mathrm{kg} /$ day (AQ) both for three days.

- the blister pack: Arsumax ${ }^{\otimes}$ tablets (Sanofi-Aventis) containing $50 \mathrm{mg}$ of AS and AQ tablets (Sanofi-Aventis) containing $153 \mathrm{mg}$ of AQ base. There were three dosing blisters and both drugs were administered following the manufacturer's instructions: (i) children below one year of age $=1 / 2$ tablet of each drug; (ii) children between one and six years of age $=$ one tablet of each drug; (iii) children above six and below 13 years of age $=$ two tablets of each drug, and (iv) above 13 years of age $=$ four tablets of each drug.

All treatments were administered under supervision in the clinic, except in 2005 when only the first dose was super- 
vised and patients were instructed to continue their treatment at home. Patients were seen on Days 0-3 inclusive during 2000-04 (Days 0, 2 and 3 in 2005), and then on Days 7, 14, 21, 28 or in between, as needed. Non attendees for scheduled clinic visits were actively sought by community health workers. Giemsa-stained thick films were read by trained microscopists and confirmed by one of the investigators $(\mathrm{PB})$.

\section{Study end points}

The end point for efficacy was the Day 28 crude cure rate calculated using Kaplan-Meier survival analysis [10] on the Intent-to-Treat (ITT) dataset (all patients who entered the study) for the whole period under study and by year; the log rank test was used to test for significance between years. Success was defined as parasite clearance that was sustained through Day 28. Failure to clear parasites and recurrent parasitaemia were considered as failures. Genotyping parasites was not done to distinguish between recrudescences and reinfections. All study withdrawals due to adverse events, irrespective of their relationship to study drug, were considered as failures. All patients lost to follow up were censored on the date they were last seen. Parasitological failures were rescued with quinine.

Safety was assessed by: (i) recording treatment emergent sign/symptom (TESS, i.e. events which were not present pre-treatment or worsened with treatment) and (ii) measuring liver (alanine, ALT and aspartic, AST transaminases and bilirubin), renal functions (creatinine) (KONELAB 60I analyser, Konelab, Finland) and haematology (haematocrit, WBC total counts), aiming for about $30 \%$ of the patients enrolled to have at least one baseline and one post-treatment sample. The common toxicity criteria for adverse events (CTCAE Version 3.0 08/09/2006) were used to evaluate and grade the severity of clinical events and laboratory measurements. Shift tables were done to show changes in severity of CTC grades between Day 0 and Day 28.

\section{Data analyses}

Data were recorded in a case record form comprising demography, parasite counts, signs and symptoms, laboratory data and adverse events at each scheduled visit. They were double keyed in Excel ${ }^{\circledR}$ using an end-user formatted sheet with online edit-checks.

Descriptive statistics are presented as counts, percentages, means and standard deviations, as appropriate. One-way ANOVA was used to assess the comparability of the patients' baseline characteristics between years and sites. Continuous data were assessed for normality using the Kolmogorov-Smirnov test; if significant, data were logtransformed and analysed using the ' $t$ ' test, if normally distributed. Otherwise the Mann-Witney U test was used for paired comparisons. Homogeneity of variance was assessed with the Bartlett test. The Welch adjusted ANOVA was carried out if variances were unequal. Between groups comparisons of continuous data were further investigated with the Tuckey-Kramer post hoc test using means (normally distributed data) or ranks (skewed data). Dichotomous variables were analysed using chi-squared or Fisher's exact tests (Freeman-Halton if more than two categories) test if the expected counts were lower than five in any cell.

Kaplan-Meier survival analysis was performed to evaluate cure rates: (i) for all the years combined, (ii) between years, and (iii) between the loose and the co-blistered products [10]. The log rank test was used to test for homogeneity between survival curves of each year and the loose and the co-blistered products. A Cox proportional hazard model of the probability of failure was done to test for the contribution of the year of treatment and products. A descending stepwise manual modelling strategy based on the likelihood ratio test between subsequent models was carried out, beginning with a saturated model containing all factors.

A p value of $<0.05$ was considered statistically significant. All tests were two-tailed. Statistical analyses were conducted with the statistical package SAS version 9.3.1 (SAS Institute, Cary, NC, USA)

Because the dosing of AS and AQ changed during the study, the doses of AS and AQ taken by patients with the loose and the blister combinations are presented in relation to two dosing schedules: (i) the recommended weight based dosing of $4 \mathrm{mg} / \mathrm{kg} / \mathrm{d} \times 3 \mathrm{~d}$ for AS and $10 \mathrm{mg} /$ $\mathrm{kg} / \mathrm{d} \times 3 \mathrm{~d}$ for AQ base, and (ii) the new age based dosing regimen with newly defined therapeutic windows of 2-10 and $7.5-15 \mathrm{mg} / \mathrm{kg} / \mathrm{d}$, respectively [11].

\section{Results \\ Baseline characteristics}

During 2000-2005, 966 patients were enrolled, of whom 723 in Mlomp (75\%), 110 in Diembereng, 27 in Kabrousse and 106 in Oussouye. The loose combination was given to 731 patients during 2000-03 and the co-blistered product to 235 patients during 2004-05. The dose was calculated on body weight for 761 patients (731 treated with the loose and 30 with the co-blistered products) and on age for 205 (all co-blister). Treatment was given supervised to 810 patients and unsupervised to 156 (co-blistered product in 2005). Table 1 shows the patients' baseline characteristics. Overall, for all the years combined, there were 30\% more male than female patients, the mean age, weight and temperature values were 13.8 years, $33.3 \mathrm{~kg}$ and $38.4^{\circ} \mathrm{C}$. The geometric mean baseline parasitaemia was $31,850 / \mu \mathrm{L}$. The mean $( \pm \mathrm{SD})$ daily doses 
Table I: Patient's baseline characteristics overall and by year of enrolment

\begin{tabular}{|c|c|c|c|c|c|c|c|c|}
\hline & year & 2000 & 2001 & 2002 & 2003 & 2004 & 2005 & 2000-05 \\
\hline Enrolled & $\mathrm{N}$ & 214 & 302 & 117 & 98 & 79 & 156 & 966 \\
\hline Sex ratio & $\mathrm{F} / \mathrm{M}$ & 0.6 & 0.92 & 0.75 & 0.69 & 1.03 & 0.7 & 0.77 \\
\hline \multirow[t]{2}{*}{ Age (years) } & mean & 12.8 & 12.9 & 14 & 16.8 & 15.7 & 14 & 13.8 \\
\hline & std & 9.5 & 10.5 & 11.6 & 14.8 & 9.8 & 11.9 & 11.2 \\
\hline \multirow[t]{2}{*}{ Body weight $(\mathrm{kg})$} & mean & 31.9 & 31 & 33.3 & 38 & 38.9 & 33.8 & 33.3 \\
\hline & std & 15.8 & 16.3 & 18 & 20.4 & 16.6 & 17.8 & 17.3 \\
\hline \multirow[t]{2}{*}{ Parasites $/ \mu \mathrm{L}$} & geomean & 32866 & 48098 & 24775 & 24394 & 39679 & 17408 & 31850 \\
\hline & std & 3.7 & 3.6 & 4.8 & 4.7 & 3.4 & 4.7 & 4.2 \\
\hline \multirow[t]{2}{*}{ Body temp. $\left({ }^{\circ} \mathrm{C}\right)$} & mean & 38.1 & 38.7 & 38.6 & 38.6 & 37.8 & 38.3 & 38.4 \\
\hline & std & I.I & 0.6 & 0.9 & I & 1.2 & 1.2 & I \\
\hline \multirow[t]{2}{*}{ AQ dose $(\mathrm{mg} / \mathrm{d})$} & mean & 333 & 320 & 351 & 414 & 437 & 399 & 359 \\
\hline & std & 156 & 152 & 178 & 242 & 170 & 189 & 179 \\
\hline \multirow[t]{2}{*}{ AS dose $(\mathrm{mg} / \mathrm{d})$} & mean & 128 & 124 & 134 & 140 & 155 & 130 & $13 \mid$ \\
\hline & std & 64 & 65 & 71 & 73 & 59 & 62 & 66 \\
\hline
\end{tabular}

of AQ and AS for all the study years were $359( \pm 179) \mathrm{mg}$ and $131( \pm 66) \mathrm{mg}$, respectively.

There were significant statistical differences for certain baseline parameters between most of the years. In particular, there was a difference in (i) body weight between 2000-2004, 2001-2003, 2001-2004, (ii) AQ dose between 2000-2004, 2000-2005, 2001-2003, 20012004, 2001-2005, 2002-2004, 2002-2005, and (iii) AS dose between 2001-2004 and 2004-2005.

The age structure of the population treated is presented in Figure 1 . Overall, $16 \%$ of patients were $\leq 5$ years of age, $30 \%$ were $6-10$ years of age, $27 \%$ were $11-15$ years of age, $11 \%$ were $16-20,8 \%$ were $21-30$ and $7 \% \geq 30$ years of age. Using these categories there was no difference between years and sites ( $p>0.05$ ). Just over half, 57\% (n

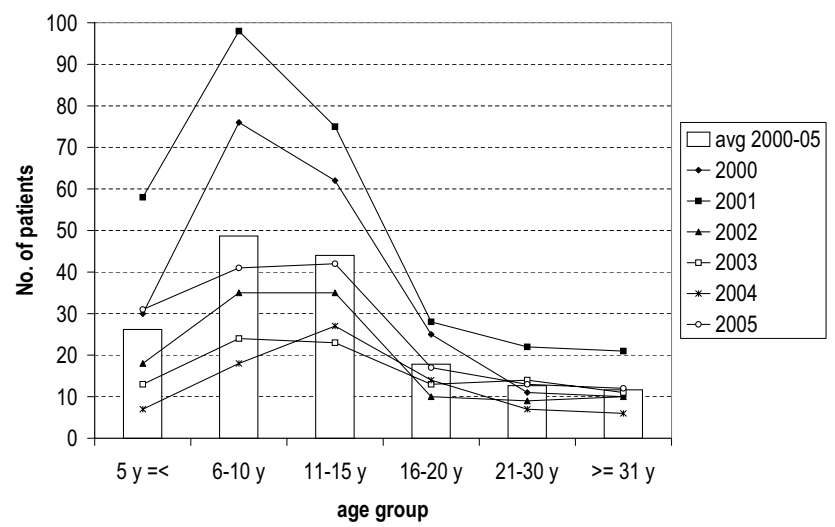

\section{Figure I}

Age structure of the malaria cases treated by year of enrolment and mean over 2000-05.
$=556)$, of the patients were aged between $6-15$ years; $46 \%(n=449)$ were under 11 years of age.

The doses of AS and AQ taken by patients compared with the weight- and age-based dosing regimens are shown in Figure 2. With both products used, doses were well within the newly defined, therapeutic windows for both drugs. For AS, doses with the loose product and the co-blistered product were similar and very close to the target dose of 4 $\mathrm{mg} /$ day; the co-blister mean doses were slightly lower with wider 95\% CIs. For AQ, doses were higher with both products than the target dose of $10 \mathrm{mg} /$ day with a tighter $95 \%$ CIs for the loose combination except for 11-15 years old.

\section{Efficacy evaluation}

The Kaplan-Meier estimates of the crude cure efficacy rate was $94.6 \%$ (95\% CI 93.0; 95.9) for all years combined. By individual years cure rates were $96.7 \%[93.2 ; 98.4]$ in $2000,94.0 \%$ [90.6; 96.2$]$ in $2001,95.7 \%$ [90.0; 98.2$]$ in $2002,94.9 \%[88.2 ; 97.8]$ in $2003,88.5 \%[79.0 ; 93.8]$ in 2004 and $95.9 \%$ [91.1; 98.1] in 2005. There were no differences $(p=0.12)$ in cure rates between years by the log rank test for homogeneity over time (Figure 3 ) All patients cleared their parasites by Day 3 (no early treatment failure, ETF); 36 patients returned with parasites during follow-up (late treatment failures, LTF) and nine were withdrawn due to an adverse event (considered as failures in our analysis - see below); 32 were lost to follow-up (censored) (Table 2). All treatment failures were retreated successfully with injectable quinine. All 36 LTFs occurred in patients under 16 years of age (20 in the age range 610 ). Efficacy was $95 \%$ in $0-10$ years and $97 \%$ in 11 and above (log rank test, $\mathrm{p}=0.03$ ). In 2005 the losses to follow up amounted to $15 \%$, while they were $\leq 3 \%$ in the other years. 

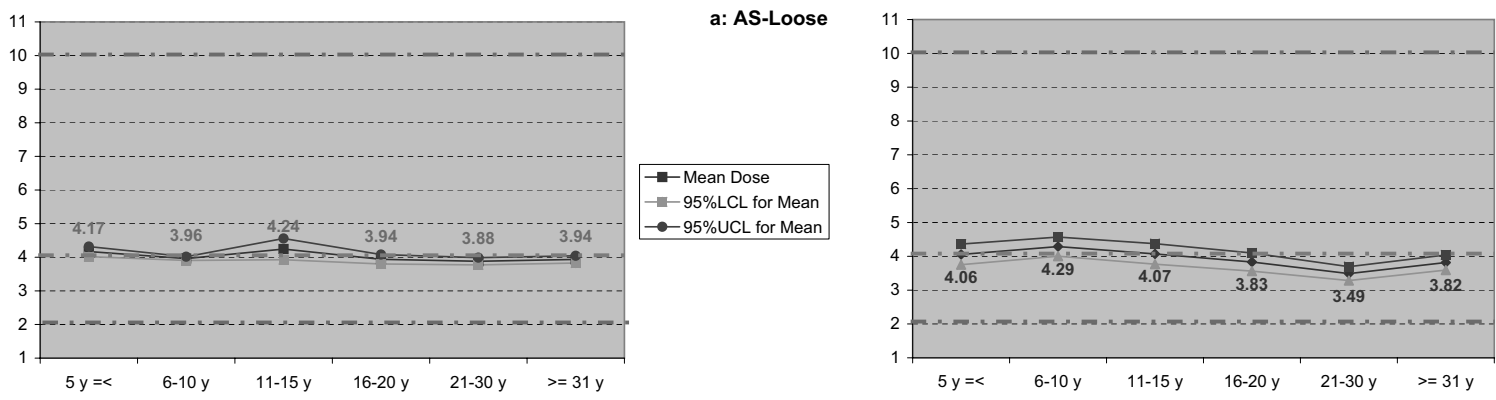

b: AS-CoBlister
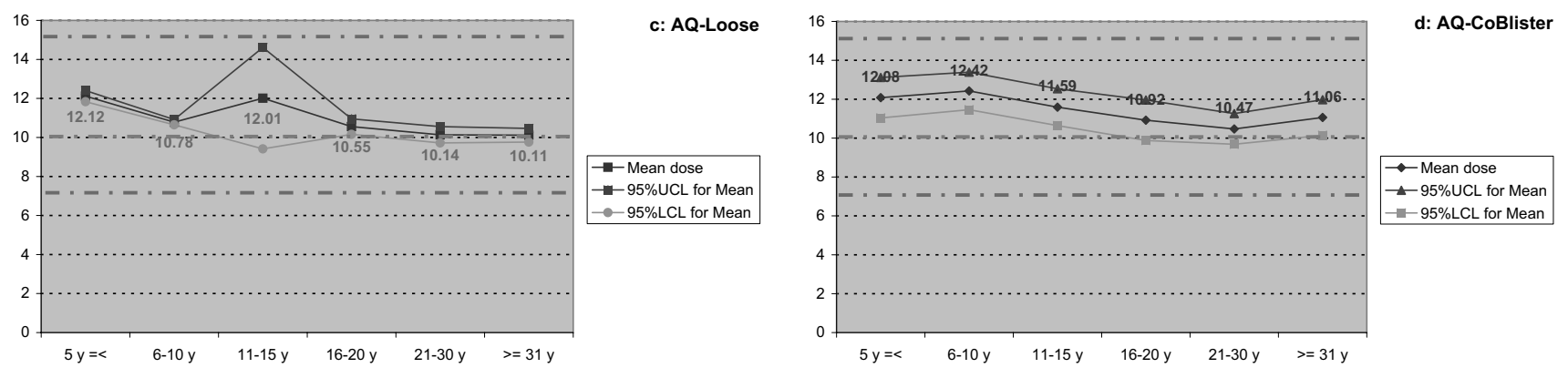

\section{Figure 2}

Mean $(95 \% \mathrm{Cl})$ doses of AS and AQ taken by patients treated with the weight based loose and aged based co-blistered drug regimens as a function of age. $a=A S$-Loose, $b=$ AS-Blister, $c=A Q$-Loose, $d=A Q$-Blister.

The Kaplan-Meier estimates of the crude cure efficacy rates were similar $(\mathrm{p}=0.14)$ between the loose $(\mathrm{n}=731)$ and the co-blistered $(\mathrm{n}=235)$ products: $95.1 \%(93.3 ; 96.5)$ vs. 93.1\% (88.8;95.8), respectively. This held true whether dosing was weight $(\mathrm{n}=761)$ or age $(\mathrm{n}=205)$ based: $94.8 \%(92.9 ; 96.2)$ vs. $94.2 \%(89.7 ; 96.7)$, respectively (p $=0.51)$ and whether treatment was supervised $(\mathrm{n}=810)$ or unsupervised $(n=156)$ : $94.5 \%(92.7 ; 95.9)$ vs. $95.9 \%$ $(91.1 ; 98.1)$, respectively $(\mathrm{p}=0.75)$.

Year of study and product used were non significant contributors to failure in a Cox proportional hazard model. Using a saturated model containing year, product, site, age, sex, weight, dose AS and dose AQ, the contribution to hazard of failure was border-line for year $(\mathrm{p}=0.06)$ but significant for the total daily dose of AS ( $\mathrm{p}=0.004)$ for a hazard of failure of 0.993 [0.988; 0.998]. Only year 2004 was statistically different from the reference year 2000 (p $=0.003)$ : the hazard of failure was four times greater in 2004 than in 2000 (hazard ratio $=4.49695 \%$ CI = [1.661; 12.168]).

\section{Safety evaluation}

Complete safety records are available for 752 patients enrolled during 2001-2005. At presentation (Day 0), all patients reported fever or had a measured fever in the clinic. Other malaria associated symptoms/signs on presentation were weakness [n = $296(29 \%)]$, headache [n =
$291(29 \%)]$, vomiting $[\mathrm{n}=133(13 \%)]$ and nausea $[\mathrm{n}=$ $113(11 \%)]$. There were no significant differences in the frequency of symptoms/signs between the different age groups or sexes.

After treatment, 69 patients (7.1\%) experienced at least one treatment emergent sign/symptom (TESS) which was either not present pre-treatment or worsened post-treatment: 54 patients suffered one TESS, 14 had two and 1 had three for a total of 85 TESSs: 36 were vomiting, 19 vertigo, 11 asthenia, 8 pruritus without a rash, 5 abdominal pain, 3 diarrhoea, 2 headaches and 1 nausea (Table 3 ). TESSs were more likely to be reported by the co-blister recipients: $54(5.6 \%)$ vs. $15(1.5 \%)(\mathrm{p}<0.0001)$ and were independent of age. For the co-blister 39 patients suffered one TESS during the study, 14 suffered 2 TESSs and one suffered 3 TESSs; of patients treated with the loose combination, 15 suffered one TESSs ( $\mathrm{p}<0.0001)$.

Nine patients, all treated with the co-blistered product (two weight-based and seven age-based), were withdrawn from the study because of a TESS for an overall, crude withdrawal rate of $0.9 \%$ : $3.8 \%$ [(co-blister) vs. $0 \%$ (loose), p < 0.0001(Table 4)]. All events were considered probably related to $\mathrm{AS}+\mathrm{AQ}$ except one case of vomiting (possibly related). In five such cases, the daily dose of AQ exceeded the target dose by $20 \%$ or more. Two patients with Grade 2 vomiting were admitted to hospital for intra- 


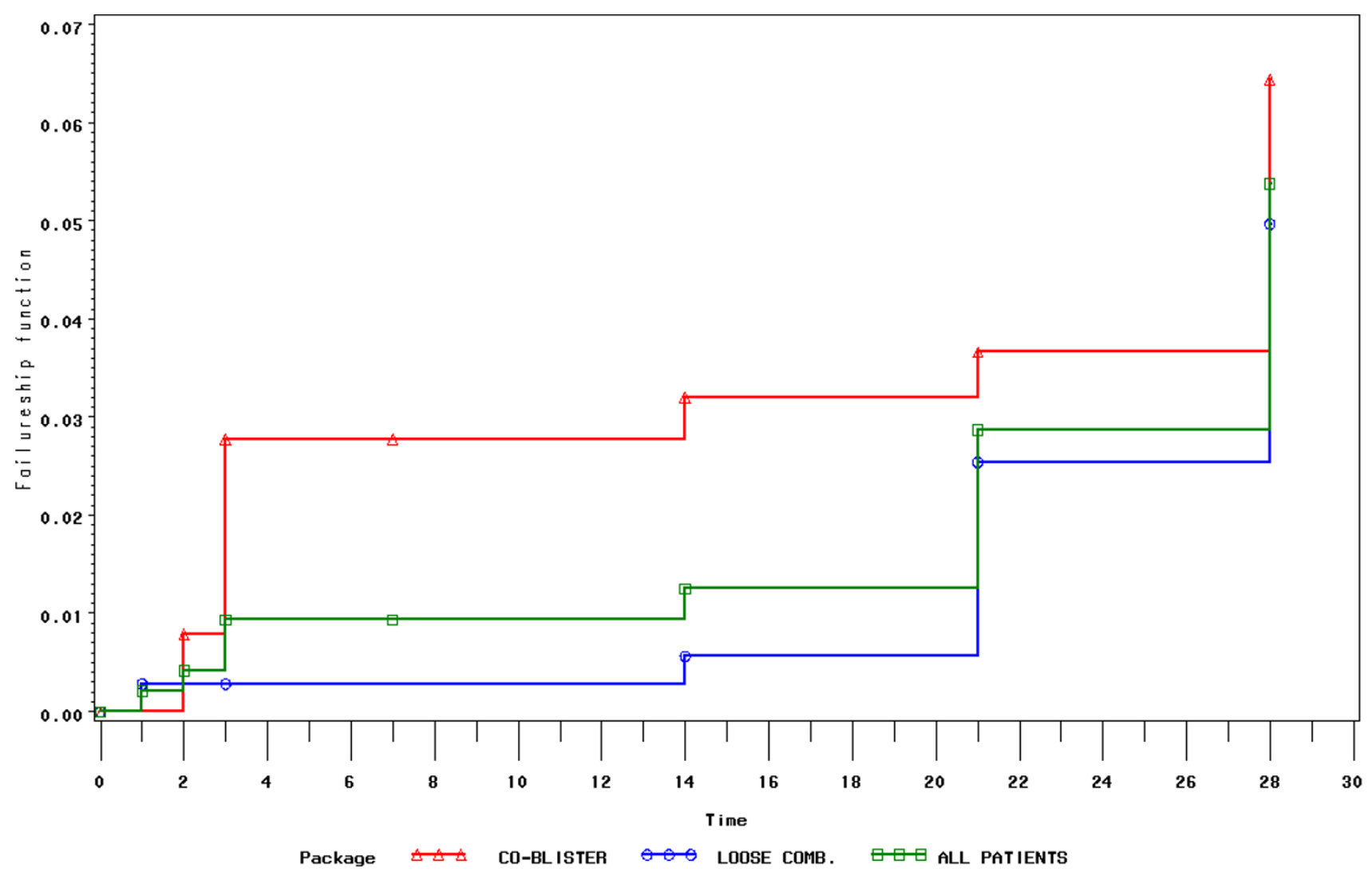

Figure 3

Kaplan-Meier of one minus survival curves to show cumulative parasitological failure rates overall (2000-05) and by year of treatment (all ages combined).

venous quinine and symptomatic treatment; they recovered well. These hospitalizations define these AEs as serious adverse events (SAEs).

For the laboratory investigations, pretreatment results were available in $33 \%, 22 \%$ and $17 \%$ of patients for haematocrit (Hct), total white blood cells (WBC) and biochemistry, respectively (Table 5). No CTC grade 4 values were present at baseline and at Day 28. One patient had a grade 4 creatinine value on Day 7 [16.5 $>6 \times$ ULN, ULN $=1,20 \mathrm{mg} / \mathrm{dL}]$ and returned to grade 0 at Day 28 .

There were no shifts between Day 0 and Day 28 from grades $0-2$ to grades 3 or 4 (Table 6). Out of 12 changes in the total WBCs, three patients changed from grade 0 to grade 1 and one patient from grade 0 to grade 2, while the remaining eight patients changed to lower grades. There were 28 changes in CTC grade for AST; four had increased

Table 2: Distribution of treatment failures and losses to follow-up by year of study.
(a) by year
2000200120022003200420052000-05

KM estimate of

96.7 (93.2-98.4)94 (90.6-96.2)95.7 (90.0-98.2)94.9 (88.2-97.8)88.5 (79.0-93.8)95.9 (91.1-98.1)94.6 (93.0-95.9) success $(95 \% \mathrm{Cl})$

\begin{tabular}{llllllc}
\hline LTF withdrawn due to & 7 & 17 & 2 & 4 & 5 & 1 \\
AE lost to follow up & 0 & 0 & 0 & 0 & 4 & 5 \\
& 2 & 1 & 3 & 2 & 1 & 23 \\
\end{tabular}

Treatment failures were late parasitological failures [LTF] and withdrawals in the Kaplan-Meier analysis. Losses to follow-up were censored in the $\mathrm{KM}$ analysis. See KM analysis in figure 3 . 
Table 3: Type, frequency and severity of Treatment Emergent Signs and Symptoms (TESS) and number of patients experiencing at least one episode

\begin{tabular}{|c|c|c|c|c|c|}
\hline \multirow[t]{2}{*}{ Symptom } & \multicolumn{4}{|c|}{ Intensity } & \multirow[t]{2}{*}{ Total $n(\%)$ of TESS } \\
\hline & Mild & Moderate & Severe & Very severe & \\
\hline Abdominal pain & & $5(10.2 \%)$ & & & $5(5.9 \%)$ \\
\hline Asthenia & & $2(4.1 \%)$ & 9 (53\%) & & II(I3\%) \\
\hline Diarrhoea & & $3(6.1 \%)$ & & & $3(3.5 \%)$ \\
\hline Headache & & I (2\%) & I (5.9\%) & & $2(2.4 \%)$ \\
\hline Nausea & & & & I (33.3\%) & I (I.2\%) \\
\hline Pruritus & & $4(8.2 \%)$ & $3(17.6 \%)$ & I (33.3\%) & $8(9.4 \%)$ \\
\hline Vertigo & $4(25 . \%)$ & 13 (26.5\%) & 2 (II.8\%) & & 19 (22.3\%) \\
\hline Vomiting & $12(75 \%)$ & 21 (42.9\%) & $2(11.8 \%)$ & I (33.3\%) & 36 (42.3\%) \\
\hline Total & $16(18.9 \%)$ & 49 (57.6\%) & 17 (20\%) & $3(3.5 \%)$ & 85 (100\%) \\
\hline
\end{tabular}

grades, from grade 0 to $1(\mathrm{n}=3)$ and from grade 0 to grade $2(n=1)$. Out of 29 , only two increased shifts were observed with ALT; one from grade 0 to grade 1 and one from grade 1 to grade 2 . One shift from grade 0 to grade 1 was observed for the serum creatinine. For total bilirubin there were one change in CTC grades from 0 to 1 and two from 0 to 2 . There were also nine decreases from grade 1 to grade 0 and four decreases from grade 2 to 0 .

There were no significant changes in mean values between Day 0 and Day 28 for the haematocrit (mean diff. $0.31 \pm$ $6.10 \%, \mathrm{p}=0.51$ ) and total WBC (mean diff. $-395 \pm 2940$, $\mathrm{p}=0.21)$ but there were significant decrease from Day 0 to Day $7(2.52 \pm 5.56 \%, \mathrm{p}<0.0001)$ and increase from Day 7 to Day $28(-1.91 \pm 4.70 \%$, p < 0.0001) for haematocrit. The mean AST, ALT and bilirubin decreased significantly while there was a small $(0.16 \mathrm{mg} / \mathrm{dL})$ but statistically significant increase in the mean creatinine values between Day 0 and Day 28 (Figure 4).

\section{Discussion}

The favourable results of this study support the policy decision of using AS+AQ in Senegal. It is premature to speculate how long this treatment will last but after six years of use, AS+AQ is still highly effective in the district of Oussouye where the rate of in vitro chloroquine resistance is $>60 \%$ [12]. The patients from this study represent approximately one third of the more than 3000 patients who have already received $A S+A Q$ as part of its deployment as first-line treatment at the district level. Reassuringly, the in vitro susceptibility of $P$. falciparum parasites to desethyl-AQ and artemisinin has not changed under drug pressure during this initial phase of deployment [12].

The efficacy of AS+AQ was well above the 90\% threshold recommended by the WHO despite the conservative approach used in analysing the data: ITT dataset, adverse events considered as treatment failures and no adjustment for PCR proven new infections. As such, this study reflects more the effectiveness of $\mathrm{AS}+\mathrm{AQ}$ in the field, while probably underestimating the real efficacy of this treatment. Interestingly, failure rates even in children under 10 years of age were considerably lower than those detected in 1998 in the same age group [7]. It is difficult to explain these differences; in both cases, 28 day crude, non PCRadjusted were measured, while patients were recruited during the rainy season in 1998 and all year round in 2000-05. Reinfections would be less frequent outside the rainy seasons; furthermore, the number of malaria cases has been decreasing after 2000 .

Despite the good parasitological efficacy, treatment did not produce haematological recovery, a softer marker of efficacy. This may have been due to a combination of a relatively high mean, pretreatment haematocrit, the negative effect of AS on reticulocytes, and the short follow up period. Haematological recovery requires more than four weeks in some malaria settings [13]. Treatment was welltolerated as testified by the very low withdrawal rate $(<1 \%)$, including two hospital admissions, because of drug induced toxicity. No significant clinical laboratory toxicities were detected.

AS+AQ was equally effective whether given based on body weight as loose combination or by age as co-blistered products (as per the manufacturer's instructions); however, the latter induced more TESS and all the treatment withdrawals due to intolerance. The use of the co-blister did result in patients receiving doses of both drugs, in $\mathrm{mg} /$ $\mathrm{kg}$, that were close to the recommended, weight based, $\mathrm{mg} / \mathrm{kg}$ dosing regimen, though the co-blistered AQ $\mathrm{mg} / \mathrm{kg}$ dose looked to be a little higher than the loose AQ and had a broader spread of the 95\% CIs. Gastrointestinal complaints accounted for seven of the nine withdrawals and were probably AQ rather than AS related, given that AS has excellent tolerability. Five patients received AQ 
Table 4: TESS requiring withdrawal from the study. All patients received the co-blistered product.

\begin{tabular}{|c|c|c|c|c|c|c|c|c|c|c|c|c|c|c|}
\hline $\mathrm{pt} \#$ & dosed by & super vised & day withdrawn & reason & $\mathrm{AE}(\mathrm{Day}=$ grade) & imputability & measure taken & Age (Years) & Weight (Kg) & Actual & Target & Actual & Target & $\Delta \%$ \\
\hline 108 & age & yes & 3 & vomiting & $\mathrm{D} 0=2 ; \mathrm{DI}=2 ; \mathrm{D} 2=\mathrm{I}$ & possible & metopimazine i.m. & 19 & 49 & 200 & 196 & 612 & 490 & $20 \%$ \\
\hline 167 & age & yes & 2 & vomiting & $\mathrm{DI}=2$ & probable & metopimazine i.m. + quinine i.m. & 18 & 47 & 200 & 188 & 612 & 470 & $23 \%$ \\
\hline 186 & weight & yes & 2 & abdominal pain & $\mathrm{DI}=2$ & probable & phloroglucinol p.o+quinine i.m. & 19 & 77 & 200 & 308 & 612 & 770 & $-26 \%$ \\
\hline 212 & weight & yes & 2 & abdominal pain + weakness & $\mathrm{DI}=2$ & probable & phloroglucinol p.o+quinine i.m. & 14 & 49 & 200 & 196 & 612 & 490 & $20 \%$ \\
\hline 266 & age & no & 3 & vomiting & $\mathrm{DI}=2$ & probable & hospitalized: metopimazine i.v. + quinine i.v. & 11 & 36 & 100 & 144 & 306 & 360 & $-18 \%$ \\
\hline 464 & age & no & 3 & vomiting & $\mathrm{DI}=2$ & probable & hospitalized: metopimazine i.v. + quinine i.v. & $11 / 2$ & 8.8 & 50 & 35.2 & 153 & 88 & $42 \%$ \\
\hline 116 & age & no & 2 & vomiting & $\mathrm{DI}=2$ & probable & metopimazine i.m. + quinine i.m. & 18 & 47 & 200 & 188 & 612 & 470 & $23 \%$ \\
\hline 8 & age & no & 3 & vertigo & $\mathrm{DI}=2, \mathrm{D} 2=2$ & probable & none & 16 & 53 & 200 & 212 & 612 & 530 & $13 \%$ \\
\hline 87 & age & no & 3 & pruritus & $\mathrm{DI}=2, \mathrm{D} 2=2, \mathrm{D} 3=2$ & probable & dexchlorphe - niramine p.o. & 16 & 59 & 200 & 236 & 612 & 590 & $4 \%$ \\
\hline
\end{tabular}


Table 5: Clinical laboratory values on D0 (pre-treatment), Day 7 and Day 28 (mean, standard deviation) and mean (95Cl) changes between Day 0 and Day 28

\begin{tabular}{|c|c|c|c|c|c|c|c|c|c|}
\hline \multirow[b]{3}{*}{ Haematocrit } & & \multirow{3}{*}{$\frac{N}{323}$} & \multirow{3}{*}{$\frac{\text { mean }}{39}$} & \multirow{3}{*}{$\frac{\text { std dev }}{6}$} & \multicolumn{5}{|c|}{ Difference vs. D0 } \\
\hline & & & & & \multirow[t]{2}{*}{$N$} & \multirow[t]{2}{*}{ Mean } & \multicolumn{2}{|c|}{$95 \% \mathrm{Cl}$} & \multirow[t]{2}{*}{ Paired t-test } \\
\hline & D 0 & & & & & & & & \\
\hline & D 7 & 233 & 36.3 & 5.6 & 228 & -2.5 & -3.2 & -1.8 & $<.0001$ \\
\hline & D 28 & 171 & 38.8 & 5 & 168 & -0.3 & -1.2 & 0.6 & 0.51 \\
\hline \multirow[t]{3}{*}{ WBCs } & D 0 & 212 & 6421 & 2929 & & & & & \\
\hline & D 7 & 120 & 6746 & 2509 & 120 & -78.9 & -602.6 & 444.8 & 0.76 \\
\hline & D 28 & 88 & 6987 & 2598 & 86 & 395.5 & -234.8 & 1026 & 0.22 \\
\hline \multirow[t]{3}{*}{ ASAT } & D 0 & 167 & 40.2 & 38.8 & & & & & \\
\hline & D 7 & 134 & 23 & $4 I$ & 123 & -7.4 & -14.4 & -0.3 & 0.04 \\
\hline & D 28 & 106 & 21 & 22 & 101 & -15.2 & -22.1 & -8.3 & $<.0001$ \\
\hline \multirow[t]{3}{*}{ ALAT } & D 0 & 169 & 21.4 & 16.3 & & & & & \\
\hline & D 7 & 133 & 15 & 29.9 & 126 & -4 & -9.2 & 1.1 & 0.12 \\
\hline & D 28 & 105 & 11.7 & 11.7 & 103 & -9.4 & -12.7 & -6.2 & $<.0001$ \\
\hline \multirow[t]{3}{*}{ Creatinine } & D 0 & 166 & 0.6 & 0.3 & & & & & \\
\hline & D 7 & 132 & 0.8 & I.4 & 118 & 0.2 & -0.1 & 0.4 & 0.23 \\
\hline & D 28 & 106 & 0.7 & 0.3 & 100 & 0.1 & 0 & 0.2 & 0.02 \\
\hline \multirow[t]{3}{*}{ Bilirubin } & D 0 & 156 & 7 & 6.2 & & & & & \\
\hline & D 7 & 123 & 3.3 & 2.2 & 104 & -3.9 & -5 & -2.8 & $<.0001$ \\
\hline & D 28 & 75 & 4.2 & 4.3 & 71 & -3.4 & -5.1 & -1.6 & 0.0004 \\
\hline
\end{tabular}

D0 = pre-treatment.

std dev = Standard Deviation.

$95 \% \mathrm{Cl}=$ Confidence Interval at $95 \%$ level for estimated mean change

doses $\geq 20 \%$ than the weight based dose of $10 \mathrm{mg} / \mathrm{kg}$ and four were within the $15 \mathrm{mg} / \mathrm{kg}$ upper limit of the newly defined therapeutic window. Never the less, the AQ dose may have contributed to their gastro-intestinal complaints.

The results obtained when patients are dosed more loosely by age are important because more practical regimens may expose patients to drug doses that are outside of the recommended, strictly defined, weight based doses. A more refined practical dosing has been developed for a new, aged dosed, fixed dose combination of AS+AQ [14]. It is generally accepted that making treatments easier to understand and use by patients or e.g. their parents results in better compliance and that using fixed dose combinations enhances this $[15,16]$. The AS-AQ fixed-dose combi- nation will become available later in 2007 and plans are afoot to test it in Casamance. Its tolerability will be evaluated.

No cases of hepatitis or severe leukopenia (as a surrogate marker of neutropaenia) were detected, the two amodiaquine-associated toxicities that have caused fatalities in the past, when used as prophylaxis in travelers [16]. However, the number of closely monitored patients was too low to detect rare toxicities, and differential WBC counts could not be done. Intensified monitoring of possible AS + AQ related AEs needs to be conducted in parallel with its widespread deployment, a practice which should be adopted systematically with all other ACTs.

Table 6: Shift tables of CTC grades from Day 0 to Day 28 by CTC grading

\begin{tabular}{|c|c|c|c|c|c|c|c|c|c|c|c|c|c|c|}
\hline \multirow[b]{2}{*}{ Day 0} & \multicolumn{3}{|c|}{ WBC Day 28} & \multicolumn{3}{|c|}{ ASAT Day 28} & \multicolumn{3}{|c|}{ ALAT Day 28} & \multicolumn{2}{|c|}{ Creatinine Day 28} & \multicolumn{3}{|c|}{ Total Bilirubin Day 28} \\
\hline & G.0 & G. I & G.2 & G.0 & G.I & G.2 & G.0 & G.I & G.2 & G.0 & G.I & G.0 & G.I & G.2 \\
\hline Grade 0 & 61 & 3 & 1 & 63 & 3 & 1 & 84 & 1 & 0 & 23 & I & 53 & 1 & 2 \\
\hline Grade I & 5 & 2 & 0 & 20 & 5 & 0 & 17 & 0 & 1 & 0 & 0 & 9 & 0 & 0 \\
\hline Grade 2 & 1 & 0 & 1 & 5 & 4 & 0 & 0 & 0 & 0 & 0 & 0 & 4 & 0 & I \\
\hline Grade 3 & 1 & 0 & I & 0 & 0 & 0 & & & & & & & & \\
\hline
\end{tabular}

CTC grading: $\mathrm{G} 0$ = none; $\mathrm{Gl}=$ mild $; \mathrm{G} 2$ = moderate; $\mathrm{G} 3$ = severe $; \mathrm{G} 4$ = very severe 

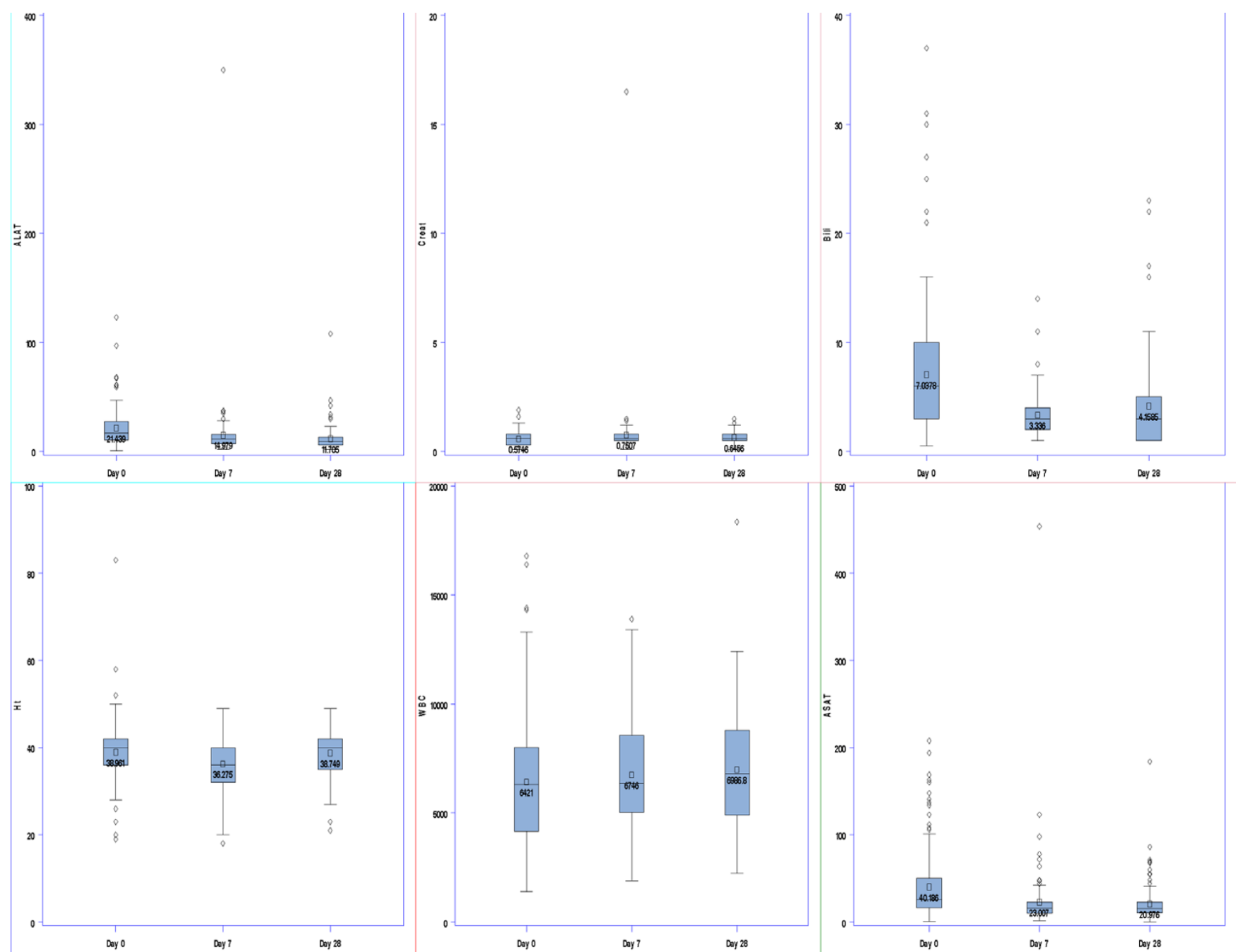

Figure 4

Boxplots of laboratory parameters over time. (ALT = aspartate transaminase; $A L T=$ alanine transaminase).

This study confirms that, in this area of moderate/intense transmission, the risk of clinical malaria is present throughout life and that children between 6-15 years of age are most affected. This is important as clinical studies in these areas normally enroll patients up to 10 years old, and thus would miss an important segment of the patient population. In this study, although treatment was statistically less efficacious in children under 11 years of age than in older patients, efficacy rates were still high in both, $95 \%$ and $97 \%$, respectively.

To conclude, this field study has shown a high and stable cure rate for AS+AQ even when dosed by age. Tolerability was good but continued intensive safety monitoring is still required in large numbers of patients for this ACT. Further research is planned to continue on the AS/AQ fixed dose combination.

\section{Competing interests}

The author(s) declare that they have no competing interests.

\section{Authors' contributions}

All authors read and approved the final manuscript.

- P Brasseur was the Principal Investigator of the study. He contributed to the concept, protocol, analysis and reporting of the study, and contributed to the preparation of the manuscript. He personally contributed to the treatment, follow-up of patients and quality control of the study.

- P Agnamey contributed personally to the treatment and follow-up of patients.

- O Gaye participated in designing the concept and protocol of the study and supervised study conduct. 
- M Vaillant designed and conducted the analyses, contributed to the preparation of the manuscript.

WRJ Taylor and P Olliaro contributed to the concept of the project; design of the protocol and analyses, reporting of the study, and to the preparation of the manuscript.

\section{Acknowledgements}

We are grateful to the personnel of the health posts and the patients of the district of Oussouye.

This study was funded by the UNICEF/UNDP/WB/WHO Special Programme for Research \& Training in Tropical Diseases (TDR), the French Ministry of Foreign Affairs (FAC 2000) and Ministry of Research (PAL+). The Drugs for Neglected Diseases initiative (DNDi) contributed to the conduct of laboratory tests, data management and analyses. The drugs were donated by Sanofi-Aventis. The funders had no role in study design, data collection and analysis, decision to publish, or preparation of the manuscript.

The opinions expressed in this paper are those of the authors and may not reflect those of their employing organizations. $\mathrm{PO}$ is a staff member of the WHO and WRJT was a member at the time of the conduct of the study; the authors alone are responsible for the views expressed in this publication and they do not necessarily represent the decisions, policy or views of the WHO.

\section{References}

I. Brockman A, Price RN, Van VUGT M, Heppner DG, Walsh D, Sookto P, Wimonwattrawatee T, Looareesuwan S, White NJ, Nosten F: Plasmodium falciparum antimalarial drug susceptibility on the north-western border of Thailand during five years of extensive use of artesunate-mefloquine. Trans $R$ Soc Trop Med Hyg 2000, 94(5):537-544.

2. Nosten F, Van Vugt M, Price R, Luxemburger C, Thway KL, Brockman A, McGready R, Ter Kuile F, Looareesuwan S, White NJ: Effects of artesunate-mefloquine combination on incidence of Plasmodium falciparum malaria and mefloquine resistance in western Thailand: a prospective study. Lancet 2000, 356(9226):297-302.

3. Barnes K, Durrheim DN, Little F, Jackson A, Mehta U, Allen E, Diamini SS, Tsoka J, Bredenkamp B, Mthembu DJ, et al.: Effect of artemether-lumefantrine policy and improved vector control on malaria burden in Kwazulu-Natal, South Africa. PLoS Med 2005, 2(I I):330.

4. Snow RW, Marsh K: The consequence of reducing transmission of Plasmodium falciparum in Africa. Adv Parasitol 2002, 52:235-264.

5. Sokhna CS, Trape JF, Robert V: Gametocytaemia in senegalese children with uncomplicated falciparum malaria treated with chloroquine, amodiaquine or sulfadoxine+pyrimethamine. Parasite 200I, 8:243-250.

6. Agnamey P, Brasseur P, Eldin de Pecoulas P, Vaillant M, Olliaro P: Plasmodium falciparum in vitro susceptibility to antimalarial drugs in Casamance (south-western senegal) during the first five years of routine use of artesunate-amodiaquine. Antimicrob Agents Chemother 2006, 50:1531-1534.

7. Adjuik M, Agnamey P, Babiker A, Borrmann S, Brasseur P, Cisse M, Cobelens F, Diallo S, Faucher JF, Garner P, et al.: Amodiaquineartesunate versus amodiaquine for uncomplicated Plasmodium falciparum malaria in African children: a randomized multicentre trial. Lancet 2002, 359:1365-1370.

8. Agnamey P, Brasseur P, Cisse M, Gaye O, Dumoulin J, Rigal J, Taylor WR, Olliaro P: Economic evaluation of a policy change from single-agent treatment for suspected malaria to artesunateamodiaquine for microscopically confirmed uncomplicated falciparum malaria in the Oussouye District of south-western Senegal. Trop Med Int Health 2005, 10(9):926-933.
9. Brasseur P, Guiguemde R, Diallo S, Guiyedi V, Kombila M, Ringwald $P$, Olliaro $P$ : Amodiaquine remains effective for treating uncomplicated malaria in West and Central Africa. Trans $R$ Soc Trop Med Hyg 1999, 93:645-650.

10. Stepniewska K, White NJ: Some considerations in the design and interpretation of antimalarial drug trials in uncomplicated falciparum malaria. Malar J 2006, 5: 127.

II. Taylor WRJ, Terlow DJ, Olliaro P, White NJ, Brasseur P, Ter Kuile FO: Use of weight-for-age-data to optimize tablet stregth and dosing regimen for a fixed-dose artesunate-amodiaquine combination for treating falciparum malaria. Bull World Health Organ 2006, 84:956-964.

12. WHO: Assessment and monitoring of antimalarial drug efficacy for the treatment of uncomplicated falciparum malaria. WHO/HTM/RBM/200350 2003.

13. Price R, Simpson J, Nosten F, Luxemburger C, Hkirjaroen L, Ter Kuile $\mathrm{F}$, Chongsuphajaisiddhi T, White N: Factors contributing to anemia after uncomplicated falciparum malaria. Am J Trop Med Hyg 200I, 65(5):6I4-622.

14. Connor J, Rafter N, Rodgers A: Do fixed-dose combination pills or unit-of-use packaging improve adherence? A systematic review. Bull World Health Organ 2004, 82( 12 2):935-939.

15. Ratsimbasoa A, Randrianarivelojosia M, Millet $P$, Soares JL, Rabarijaona L, Rakotoson B, Malvy D, Menard D: Use of a pre-packadged chloroquine for the home management of presumed malaria in Malagasy children. Malar J 2006, I 4(5):79.

16. Taylor WRJ, White NJ: Antimalarial drug toxicity. A review. Drug Saf 2004, 27:25-61.
Publish with Bio Med Central and every scientist can read your work free of charge

"BioMed Central will be the most significant development for disseminating the results of biomedical research in our lifetime. "

Sir Paul Nurse, Cancer Research UK

Your research papers will be:

- available free of charge to the entire biomedical community

- peer reviewed and published immediately upon acceptance

- cited in PubMed and archived on PubMed Central

- yours - you keep the copyright

Submit your manuscript here:

http://www.biomedcentral.com/info/publishing_adv.asp
BioMedcentral 